\title{
Communicative management in present-day university
}

\author{
Olga Petryshyna ${ }^{1, *}$ and Mariya Boyko ${ }^{1, * *}$ \\ ${ }^{1}$ Ternopil Volodymyr Hnatiuk National Pedagogical University, 2 M. Kryvonosa Str., Ternopil, 46027, Ukraine
}

\begin{abstract}
In modern academic community not only communication management plays a great role. Monitoring of expectations, awareness of communicative needs, the course and results of communicative interaction, barriers hindering rational managerial decisions are also of large importance. Everything done by participants of the learning process to solve strategic and tactical tasks of a university development requires an effective exchange of information. The main prerequisite for the effective business communication is the understanding that the possibility to achieve the goals of interaction increases if it is properly organized, if an atmosphere of mutual understanding, trust and cooperation is created. In present-day conditions, university managers must have communicative, managerial competencies, knowledge of communication theory and applied approaches to the process of its implementation. Mastering the skills of communicative influence contributes to the formation of a positive image of an institution and helps to achieve educational goals. While monitoring communicative management at Ternopil Volodymyr Hnatiuk National Pedagogical University, we have revealed the students' deep understanding of its essence, opportunities, mechanisms, and practice of implementation in the academic community. Communicative management resources provide effective management decisions and create a comfortable academic setting to meet the needs of all participants in the learning process.
\end{abstract}

\section{Introduction}

Communication is one of the prerequisites for successful management of a modern university, the process of continuous exchange of information, the mechanism of effective decision-making and communication between the subjects of internal and external settings. The role of communicative management in the academic setting lies in the interaction of all participants in the learning process, information being the main resource and communication its technology. Nowadays, communicative management in higher education has a more formal, declarative expression, despite a large number of theoretical and practical research and study aids. On the other hand, academic institutions, now competing fiercely in the market of educational services, are aware of their powers and functions, adapt business management experience to their specifics, try to use communication opportunities as a real resource and, accordingly, look for optimal ways to manage them. The essence of communicative management in the learning setting lies in implementing a purposeful, reasonable and informative influence of the subject on the object, making management decisions, mastering quality methods and tools [1].

The relevance of the study subjects to the need to justify the importance and pragmatic role of communication in management processes, rational decision-making, establishing a productive balance in the present-day academic setting. Approaches developed by the theory of

\footnotetext{
*e-mail: petryshyna@tnpu.edu.ua

**e-mail: mariyaboykodek@gmail.com
}

communication require careful analysis to focus on effective communication traditions, mechanisms, strategies and tactics, overcoming stereotypes about communication at a university. The purpose of the article is to demonstrate the essence of communicative management, to substantiate the peculiarities of its development in the academic setting as well as to describe on the basis of practical research (experiment) the modern vision of participants of the educational process the dynamics and prospects of communicative management in a present-day university.

\section{Communicative management in the scope of strategies and prospects of a university development}

The systematically organized communication process allows to ensure the coordinated work of all structural units of a university, to improve communication skills, to overcome communication barriers in the process of management functions optimization. Management functions are relatively separate areas of management allowing you to influence the management object to achieve the goal. A. Fayol, one of the founders of the management theory, distinguished the following management functions: planning, organization, motivation, coordination and control [2].

In the communicative management these basic functions include:

- definition of communication goals and ways to achieve them; 
- organization of communicative actions;

- motivation for communicative collaboration;

- coordination of interaction of all participants of the learning process;

- control over the course of professional communication;

- adjustment of its results.

Thus, communicative management is a professional activity aimed at achieving effective communication within the university as well as with the external setting through the implementation of communication policy. Communication policy involves defining the goals of communication, ways to achieve them, the content of information, and the quality of feedback.

Conceptual, communicative and managerial competencies are the basis of communicative management in the academic setting. The conceptual competence involves generation and implementation of ideas, approaches, management models and peculiarities of their development, analysis of factors influencing the formation of the communication system at a university. By the communicative competence we mean language proficiency that allows you to successfully solve the basic tasks of communication, the use of appropriate techniques relevant to a particular communicative situation. These are also strategies of behavior in academic interaction allowing you to build effective communication in accordance with the goals and conditions of professional and interpersonal interaction and requests for self-development. The basis of managerial competence is formed by knowledge of management theories, its laws and principles, the implementation of classical and modern (innovative) functions of managing the learning process at a university, mastering the technology of management decisions [3].

A present-day university setting in Ukraine requires from its authority, teachers, and students to develop advanced communication skills that not only reflect the level of communicative competence and ensure the psychological security of the team, but also present the communication culture of the institution as a whole. Communicative management, as well as other spheres of functional management, arises from the purpose and strategy of the university development, is realized in tactical decisions, has its own aims and programs. Communicative management explores the prospects of a university, creates the most effective levers of its influence as a whole, taking into account the nature of its functioning in the higher education system, and short- and long-term management decisions.

When it comes to communicative management in the academic setting, it should be understood that in different situations all participants of the learning process can be the subject of management:

- a student: while performing public duties as a monitor of the group, a head of the student government; during the teaching internship in secondary or higher educational institutions etc.;

- a lecturer as a person who organizes the learning process within a particular course and the upbringing process, monitors and adjusts its course and results; as a guarantor of the programme of study taking into account modern requirements for the quality of education and correlating the work of stakeholders, a support group, students, etc.;

- an university authorities: each head of the structural unit (heads of departments, deans), vice-rectors and the rector perform the roles of managers at different levels, ensuring the coordinated work of micro-teams to achieve optimal corporate results - to provide high-quality educational services.

R. Savolainen distinguishes between the issues of information exchange and knowledge exchange considering "information sharing and knowledge as modes of human activity" [4]. These considerations should be taken into account in our further researches on the peculiarities of communication in academia, where information is a resource, and knowledge is a result.

Business communication in the academic setting takes place according to its own rules and laws determined by the mission and pragmatic tasks of modern universities. Nowadays, this type of communication in Ukraine is undergoing rethinking and transformation due to a number of factors:

- education reform;

- relative autonomy of universities;

- penetration of certain business laws (including the laws of communication in this area) into the academic setting;

- relative weakening of conservatism, stereotyped academic communication.

The theory and practice of public communication have developed many approaches and concepts that interpret individual, group and mass communication depending on the characteristic features of participants, environment, goals and objectives of communication etc [5]. We attempted to adjust their relevance to the peculiarities of communication management in academia, considering specific features of participants of the communicative process, education managers' expectations and a university mission in general.

G. Morgan notes that productivity, accuracy and efficiency are the most valuable qualities of such characteristics which are expected from a well-designed, coordinated mechanism. Morgan uses the metaphor of a mechanism, as it reveals important parallels between mechanical devices and how managers traditionally think about their organizations [6]. According to the classical theory of management, lecturers in higher educational institutions are seen as cogs in huge university mechanisms that function harmoniously when algorithms are laid down, the range of their movement is clearly defined, actions are worked out and motivated by appropriate incentives (salary, bonuses, honors, etc.). Lecturers ("mechanisms" in other words) obtain academic degrees according to the established scheme, perform repetitive tasks, teach the same disciplines, hone the evaluation mechanism according to the same scale, prepare students according to the 
established algorithm. Finally, a university can be seen as an integral part of the country's educational mechanism, and educators at every level feel most at ease when it is run as a whole.

$\mathrm{K}$. Weick believes that innovation is hindered or prevented by hierarchical structures, the dominance of team communication, and standardized work procedures. According to the scholar, a present-day university as a living organism in order to survive must constantly adapt to changing conditions (reforms, political conditions, labor market requirements etc.). We agree with the researcher's view that organizations survive and prosper only when communication between their members is interactive and constitutes a free exchange of information [7].

The cultural approach to communication requires a serious attitude to the language of representatives of the academic setting, careful analysis of direct and contextual meanings and subtexts to find a common to all participants meaning that underlies any organization, such as "teaching as I live", "educational mission", "teacher is forever", "teach with love", "I learn by teaching". For example, in M. Pacanowsky and N. O'Donnel-Trujillo's understanding, culture is not what the organization has, but what the organization is [8].

In his critical theory of communication, S. Deetz criticizes managers' excessive concern about providing control as the best way to reduce costs and increase efficiency. How does it work in academia? University management control in action is well illustrated by various types of formalized reporting (on research, career guidance, educational and other activities), the creation of which works little in the interests of students. A unity (formation) is created in which many people live, but few have the right to vote on the structure of the company or the decisions it makes. Of great interest is S. Deetz's opinion of destructive role of "managerialism" in the organization, which he defines as a systematic logic, a set of routine practices, and ideology that values control over all other concerns [9]. The value of the scholar's views lies in his departure from the philosophy of total control in the organization. Instead, he suggested the concept of decision-making as an open dialogue of all stakeholders. Deetz calls this practice codetermination. Considering a constructive view of communication, codetermination, according to S. Deetz, represents "collaborative constructions of self, other, and the world" [10].

The core of this process is communication as necessary condition of this activity and the way to implement the needs of the subjects in each other.

Hence, the interaction of the subjects of the educational process is an integrity that is demonstrated simultaneously as the unity of opposite types of relationship (subject-subject, subject-object), opposite types of content exchange (spiritual and practical), opposite ways of exchange (activity and communication).

R. Hirokawa and D. Gouran examine management as a permanent interaction representatives of this direction, believe that interaction in the team, where everyone is interested in high performance and at the same time has their own conceptual vision, factual material, ideas, decision mechanisms etc, positively affects the final outcome [11].

Interaction of participants of the learning process is understood as a multifaceted phenomenon, namely:

- social - it is characterized by the implementation of objectively existing connections of participants of the learning process with the outside world;

- psychological - it is characterized by a process of mutual understanding, empathy, cooperation;

- pedagogical - specially organized, purposeful processes, as a result of which participants of interaction undergo positive transformations.

This interaction of participants of the learning process should be a holistic open system with its own structure, external and internal relations, a set of certain functions, including management. This system contains subjective, content-target, organizational and effective components. Its openness is ensured by connections with other pedagogical and social systems.

The following criteria that determine the effectiveness of pedagogical interaction can be distinguished:

- the learning process participants' readiness;

- openness to interaction with each other in the academic environment;

- positive interdependence of participants of interpersonal interaction (awareness of a common goal, availability of resources, joint efforts to solve problems);

- the right of every participant of interaction to authenticity;

- awareness of individual and group responsibility (participants' internal and external motivation to joint activities);

- the ability to meet basic interpersonal needs in the process of joint activities and communication;

- supportive interaction, which provides a favorable psychological climate of interaction;

- highly developed social and communication skills;

- reflexive analysis of one's own behavior as compared to social behavior of other participants, etc.

These criteria of interaction help to create necessary prerequisites that would promote the formation of partnership between participants in the learning process, help managers of educational institutions establish effective communication in the academic environment.

The content of interaction is revealed both at the level of individual contacts and in the context of common activities. The content of the relationship between the participants of the common activity is the correlation of the individual contribution of each of the participants to the common issue. The pedagogical process is the process in which social ideas are transformed into personality qualities.

The main features of joint activities in the academic environment are: 
- common goals of participants of interaction (joint activities which consist in achieving goals that are not available or partially achievable to an individual;

- joint activities are appropriate when conscious goals are set in advance);

- participants of joint activities, besides individual motives, must have motivation to work together, i.e. to form general motivation to achieve a goal;

- distribution of roles between participants of interaction;

- combining of individual and group activities, coordinated implementation of distributed and combined individual activities of all participants;

- need for management and self-management;

- a single result common to all participants.

Different views on communicative management prove that due to the academic, communicative and managerial culture of students, teachers, managers, interaction in the academic environment becomes effective.

Different forms of communication in academia (telephone conversations, meetings, conversations, business negotiations etc.) are effective under the condition of the implementation of basic communication and management skills: the ability to make a convincing impression, to speak, to listen, to use nonverbal means. Moreover, in formal (provided by the management model) as well as informal (interpersonal) communication, the implementation of these skills is important for the implementation of management tasks in the field of education. The study of the peculiarities of communication in the academia shows the existence of a number of barriers to communication. They lead to the decrease in the efficiency of the communicative process and at the same time catalyze the search for optimal models of interaction. The most notable barriers are the following: misunderstanding of the importance of the message; incorrect setting of consciousness; errors in wording the message; low persuasiveness; inability to control oneself.

The educational environment should create prerequisites for self-realization and communication, it should be aimed at ensuring that everyone can develop:

- the ability to think critically and speak independently;

- the ability to make independent decisions;

- the ability develop emotional intelligence;

- the ability form the self-awareness of each participant as a team member;

- the ability to promote the coordination of external needs and internal motives for self-development and selfrealization of all participants in the educational process.

Properly established communication allows you to solve any task. This is not a pointless "chatter", as skeptics of communication theory point out, a meaningless process that takes time and prevents the formulation of an unambiguous, individual solution. This is, rather, an opportunity for all members of the team to speak out in order to produce optimal, most rational solutions [12].
What is communication?

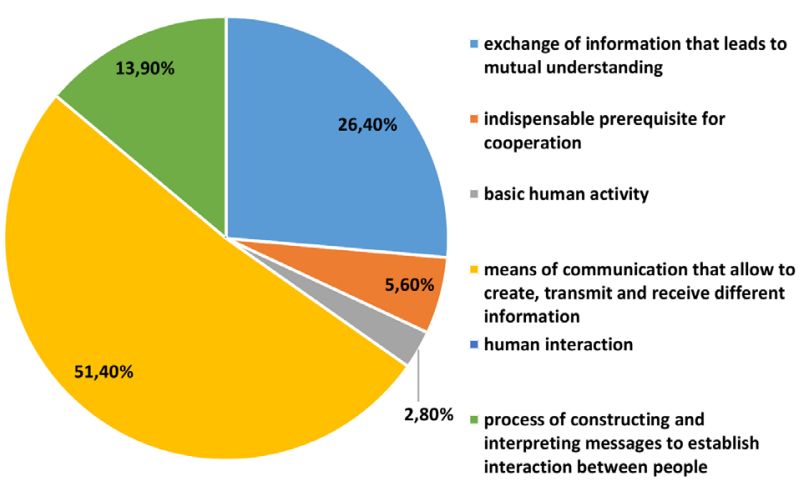

Figure 1. The students' understanding of the concept of communication

\section{Monitoring of the peculiarities of communicative management in the academic setting of a present-day university from students' perspective}

We conducted a survey in Ternopil Volodymyr Hnatiuk National Pedagogical University in which 623 respondents took part. It was aimed at discovering the level of understanding the processes underlying communicative management, participation in decision making and setting the university development strategies.

The research shows that respondents focus on the need for modern forms of communication in academic management processes.

Most respondents understand communication as a mechanism to transmit information, as well as to cooperate, collaborate and achieve common results (see figure 1).

In the students' opinion, interpersonal contacts and interaction are the most productive ways of managerial communication in modern academia. This is natural, because attention to the educational needs of students is rather a request that has formed a student-centered approach - the philosophy of modern progressive universities.

It is quite bold and brave to interpret the university in terms of communication as a team in which each participant is interested in achieving results through the expression of their ideas, considerations and actions in designing and making management decisions. As we can see, the students demonstrate not only self- sufficiency, but also willingness to take responsibility for the organization of the learning process, try to be not passive but active participants and, most importantly, to influence management decisions through communication. On the other hand, it is comforting that the respondents are aware of the dynamics of the learning process, understand that it is an open, not a static system that responds to external and internal changes, thus constantly changing, updating and improving. The choice of the option "cultural setting" indicates a shift of emphasis from pragmatic to cultural, value aspects. In this we see the respondents' deeper understanding of 


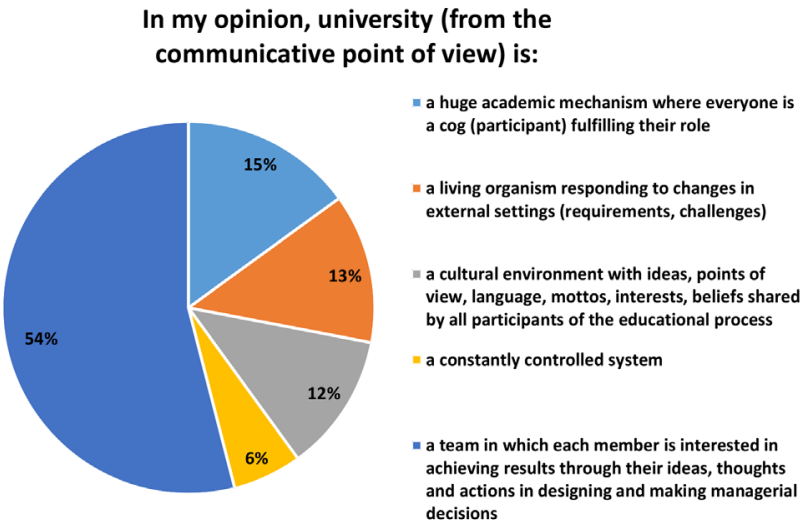

Figure 2. Understanding of the university from a communicative point of view as we can see, majority of the respondents consider contradiction between

the tasks and the mission of a modern university being not only an institution where education is obtained and competencies are formed, but also a space in which values of educated people and elites are gelled (see figure 2).

As we can see, majority of the respondents consider contradiction between expectations and real messages to be the main barrier in establishing effective academic communication. We think this contradiction can be overcome by monitoring not the very course of the learning process, but the attitudes, plans and goals set by students while being in the status of applicants. Fairly frequent answers about not realizing the importance of messages, their content, as well as not meeting communication needs as serious obstacles to establishing productive interaction in a modern university proved to be rather expected. We found such considerations of students earlier, while teaching the courses "Public Communication", "Management in Education", "Rhetoric", "The Ukrainian language (for professional purposes)". Thus, we should not underestimate the importance of the linguistic aspect in academic communication - mastery of an arsenal of communicative strategies and tactics, communicative qualities of a language (accuracy, conciseness, emotionality and expressiveness etc.), rhetorical knowledge and skills and so on (see figure 3 ).

The respondents' treatment of the essence of communicative management showed a certain polarity. On the one hand, there still exists the stereotype of authoritarian government in academia, where subordination and hierarchy are reflected in communication as well as in the learning process. On the other hand, a democratic, progressive vision of management processes in a modern university is reduced to the rational interaction of all participants endowed with an appropriate level of linguistic and communicative competencies (see figure 4).

The students consider interpersonal (person-to-person) communication the most productive form of communication in the educational environment, which indicates the participants willingness to interact with each other. Group and intergroup forms communication are, on the contrary, the least productive (see figure 5).

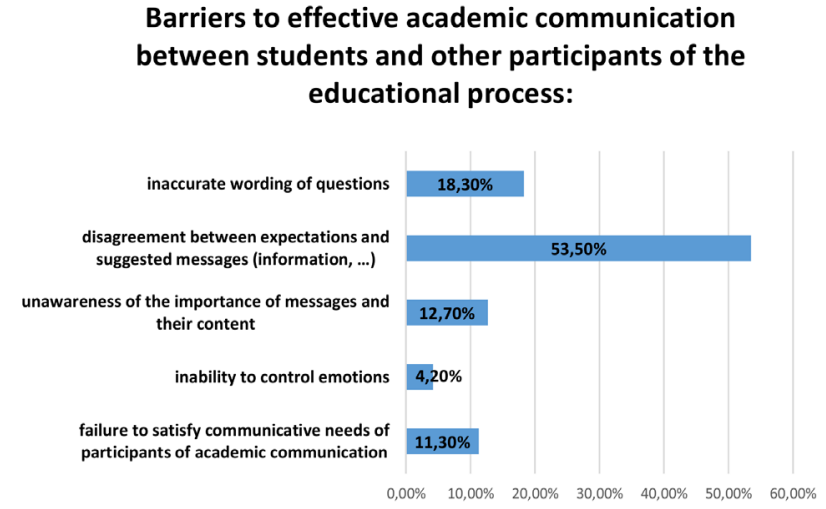

Figure 3. Understanding of the university from a communicative point of view as we can see, majority of the respondents consider contradiction between

\section{Communicative management of a present-day university reflects}

(choose not more than 3 options):

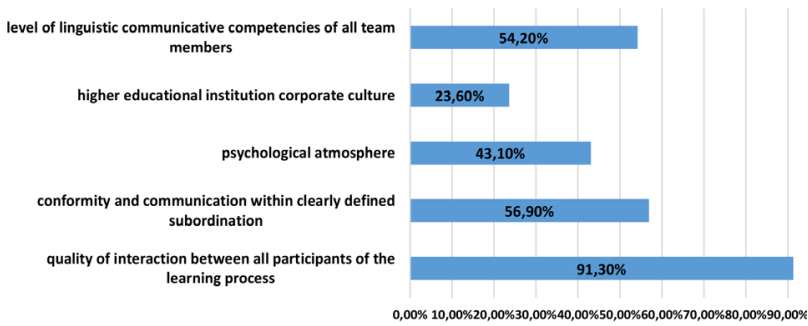

Figure 4. Correlation between the concepts of "communicative management" and "interaction in the academia"

\section{What features, in your opinion, most accurately characterize academic communication?}
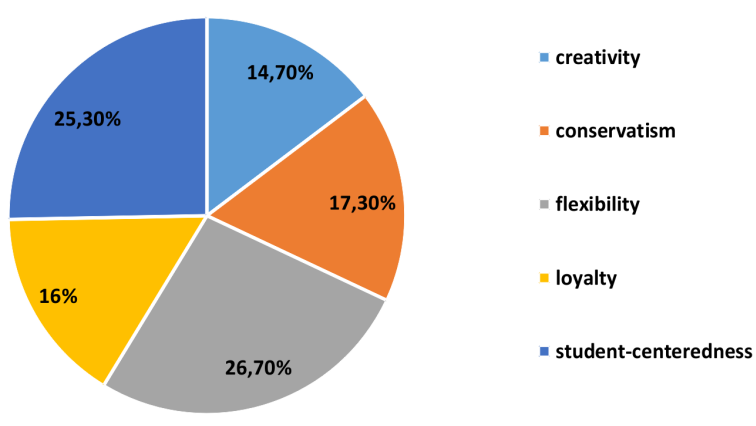

Figure 5. Forms of communication in educational environment

The features most accurately characterizing academic communication, in the opinion of the respondents, are flexibility and student-centeredness, which provide comfortable conditions to interact, develop students' individual trajectories, achieve both personal and professional goals. Public forms of communication, such as public speeches, presentations, social networking, etc. have become of huge importance. This vision reflects close con- 


\section{What forms of communication do you consider the most productive in educational environment?}

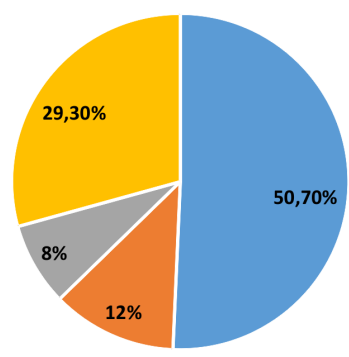

- interpersonal (person - person)

- mediated (through another member of the team, group, unit)

- group / intergroup

public (speeches, presentations, access to social networks, platforms) their conceptual, communicative and managerial competencies affect the achievement of the goals of higher educational institutions. In fact, communicative management allows to establish connections and communication, form the organizational structure, a system of information exchange in academia and meet the needs of the management process in general and each participant in particular. The university's relations with external entities are the key to success in positioning itself in a broad educational discourse. This contributes to the optimization of management processes, the development of the university through the powers of communicative management.

\section{References}

[1] T.F. Zenchenko, Bulletin of Luhansk Taras Shevchenko National University 50, 167 (2017)

[2] P. Druker, Management Challenges for the 21st Century (Routledge, 2007), ISBN 9780750685092

[3] M.M. Boyko, KELM (Knowledge, Education, Law, Management) 4, 10 (2020)

[4] R. Savolainen, Information Research: an international electronic journal 22 (2017)

[5] E.A. Griffin, A first look at communication theory (McGraw-Hill, New York, 2012)

[6] G. Morgan, Images of organization: The executive edition (Berrett-Koehler Publishers;, Thousand Oaks, CA, 1998)

[7] K.E. Weick, The social psychology of organizing, 2nd edn. (McGraw-Hill Humanities/Social Sciences/Languages, 1979)

[8] M.E. Pacanowsky, N. O'Donnell-Trujillo, Communication Monographs 50, 126 (1983)

[9] S. Deetz, Democracy in an age of corporate colonization: Developments in communication and the politics of everyday life (SUNY press, 1992)

[10] S.A. Deetz, Annals of the International Communication Association 17, 565 (1994)

[11] D.S. Gouran, R.Y. Hirokawa, K.M. Julian, G.B. Leatham, Annals of the International Communication Association 16, 573 (1993)

[12] M. Ionel, Strategies of communication in educational management, in Communication strategies in educational management (2017), pp. 29-30, http://www. bulgariatraining.bg/ upload/COMMUNICATION\%20STRATEGIES\%20IN\% 20EDUCATIONAL\%2OMANAGEMENT . pdf 